\title{
Analysis of special features and training methods of Dragon Boat Sports in Colleges and Universities
}

\author{
Hong-chun Jia ${ }^{1, a}$, Song-bo $\mathrm{He}^{1, \mathrm{~b}, *}$, Kai-li Ren ${ }^{2}$, Yun-peng $\mathrm{Hu}^{2}$ \\ ${ }^{1}$ Beihua University, Jilin, China \\ ${ }^{2}$ Beihua University, College of physical education, Longteng innovation and entrepreneurship \\ education base \\ *Corresponding author
}

Keywords: dragon boat movement; special features; training methods

\begin{abstract}
As the traditional dragon boat sport project has been widely developed in Colleges and universities, this paper through the analysis of special features and characteristics of college athletes of dragon boat racing, discussed from the two aspects of the basic qualities of athletes and athletes training, electronic mobilization special quality should be the body shape, body function, the three aspects of quality assessment at the same time, the training content, principles and methods are discussed.

The Chinese history of more than five thousand years has accumulated a variety of cultural forms. Dragon boat culture, as a branch of sports culture, has added vitality to the socialist cultural system. In the eighteen report, Hu Jintao pointed out, "culture is the blood of the nation and the spiritual home of the people", which reflects the party's respect for and recognition of the national culture. As a traditional sport, dragon boat has a long cultural background and unique charm, which is well received by the people. After 1990, China's dragon boat movement to the international arena, in 1994 was listed as a national Dragon Boat Race project, Chinese Dragon Boat Association was founded on 1985, which marks the transition to the standard, the size of the Dragon Boat Sport competitions. China won many times in the World Dragon Boat Championships, pushing the Dragon Boat Sport to the world, to promote and show the Chinese character and style has opened the door of national culture, inheritance and development of dragon boat culture will enrich our country sports culture content.
\end{abstract}

\section{The special features of Dragon Boat Race}

\section{Physical fitness}

The dragon boat sport is a fitness class project, the main function of the system determines the physical fitness level of athletes including sshield ring system and energy system should flood the circulatory system, including cardiovascular and respiratory system, nervous system, at the same time, sports system participation, and achieved good results in a tight game requires players to have a good body form, function and quality. Specific include: body shape, flexibility, coordination, explosive force, heart and lung function, physical fitness, etc..

Physical fitness components of athletes:

(1) for quantity, the basic physical fitness of sports is the basis of all kinds of qualities, and it is the basis for the improvement of athletes' physical training.

(2) speed, it is the most important quality of dragon boat athletes. It is a powerful guarantee for athletes to play the highest body function and achieve good results.

(3) endurance, good endurance is the key to win the competition, and it is the guarantee to ensure the normal exercise level in the long period of intense competition.

(4) coordination, flexibility, dragon boat racing is a water sport, the athletes are required to have high coordination, because the system take care of each other in person and ship, ship and water, each fulcrum of pulp are not the same, and elbow joint, shoulder joint, hip joint and other athletes to 
have good flexibility.

Skills

The Dragon Boat Sport rowers movement skill is a continuity of action, including action posture, grip paddle, paddles, oars, plug, water recovery. Among them, the paddle pulling technology is the core of Dragon Boat Sports Technology, and it is the motive force that makes Dragon Boat advance fast.

\section{Team work, hard work}

Dragon boat racing is a team sport competitions, including drummer, rower, helmsman, if a team each player's strength is very good, but with poor technology, still can not play out some of the good results. This requires cooperation between the helmsman, drummer and rower, including drummer and rower with drummer, and the helmsman of the coordination, cooperation, and the rower rower and rower cooperation.

\section{Dragon Boat Sports selection and training}

\section{Athletes selection}

18-25 years of age were most suitable for rowing, college students in this age, according to the special characteristics of dragon boat racing, without considering the athletes' psychology and intelligence, genetic factors, selection of the shape, function and physical quality in three aspects.

First of all, the material from the player's height, shoulder width, hip width, arm length etc.. Secondly, from the body function of heart rate, lung capacity, blood lactic acid and other aspects of selection. Third, athletes with better athletic qualities mainly focus on strength, speed, stamina, flexibility and coordination. Finally, from the body function of heart rate, lung capacity, blood lactic acid and other aspects of selection. Heart rate is the heart function and exercise load of the pile bearing capacity, material should be selected when the lower resting heart rate.

\section{The content, principles and methods of sports training}

(1) the training contents of Dragon Boat Sports include physical training and skill training. In the early days of training, physical training should be emphasized, and some skills training can be carried out to ensure that athletes have good physical ability and learn skills.

(2) from the initial training to the excellent performance of athletes, we must carry out the principle of gradual progress. Principle of uninterrupted system and reasonable arrangement of load principle. In the training process, to arrange the training according to the situation of athletes, to lay a good foundation at the same time, pay attention to exercise load arrangement, according to the athletes in training and competition level, and gradually increase the reasonable exercise load, to prevent the occurrence of sports injury. The principle of uninterrupted one of the most important principle is the starting point of university system, Dragon Boat athletes is low, short training time, training conditions, training process can not be interrupted, arrange to exercise recovery for the purpose of the rest.

(3) method on Dragon Boat Sport Training with other similar physical events, using repeated training method, interval training, competition training method, fartlek method and other methods.

\section{Summary}

The dragon boat sport is a collective energy and skills in one of the groups of sports, teaching material, and can quickly improve the scientific training level of athletes, colleges and universities have advanced scientific research, excellent coaches, this is where the dragon boat movement superiority. Therefore, it is a solid foundation for the development of dragon boat movement to strengthen scientific research and give full play to the advantages of Dragon Boat Sports in Colleges and universities.

\section{Acknowledgements}

This paper is a research project of Beihua University students' innovation project, horizontal topi 
c: Dragon Boat land training equipment (NO:201602014).

\section{Reference}

[1] International Sports General Administration Cadre Training center. Research on physical fitness training of high level competitive skills [M]. Beijing: Beijing Sport University press, 2009.

[2] Liu Huashan, Zheng Jiarun. Dragon boat technology and training [M].. Beijing: Beijing Sport University press, 2002 (07).

[3] China Dragon Boat Sport Development and Countermeasures Analysis of [J]. Liu sea. Sports world 2013 (08).

[4] modern dragon boat racing team technical style of [J].. Sui Wenjie Sports Culture Guide (02) 2012.

[5] of Chinese elite female athletes boat body shape evaluation model on [J]. Li Bing, Chen Gang, Wang Kanggui. Journal of Chengdu Sport University 2011 (07).

[6] Dragon Boat Sport Development in Colleges and universities of our country present situation and countermeasure research of $[\mathrm{J}]$. Pingyue, Kong Qingtao. Journal of Shanghai Second Polytechnic University 2010 (04).

[7] dragon boat culture connotation and contemporary value of Wu Guangjin [J]., Qin Tokumasu. Heilongjiang National Series 2010 (06).

[8] times of spring. Chinese martial arts and cultural heritage studies [D]. Northeast Normal University, 2008.

[9] Yang Jun, Guo Faming, Hao Yanzhen. A cultural morphological analysis of the modernization of dragon boat racing [J]. Journal of Hebei Institute of Physical Education, 2012 (6): 89-91.

[10] He Yingfeng. Analysis of the international promotion of the dragon boat movement in new form [J]. Heilongjiang Institute of interest, 2011 (35): 180. 